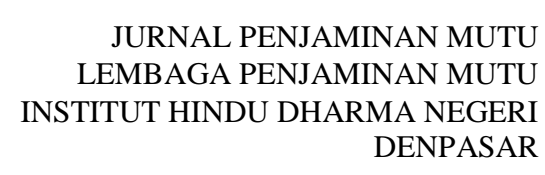

JURNAL PENJAMINAN MUTU

DENPASAR
Volume 4 Nomor 2 Agustus 2018

ISSN : 2407-912X (Cetak)

ISSN : 2548-3110 (Online)

http://ejournal.ihdn.ac.id/index.php/JPM

\title{
PERAN AKREDITASI DALAM MENARIK MINAT MAHASISWA MEMILIH PERGURUAN TINGGI SWASTA BERMUTU DI KOTA PEKANBARU
}

\author{
Oleh \\ Prama Widayat \\ Universitas Lancang Kuning-Pekanbaru \\ pramawidayat@unilak.ac.id
}

Diterima 20 Juni 2018, direvisi 31 Juli 2018, diterbitkan 31 Agustus 2018

\begin{abstract}
The ability of the community to meet the needs of life is increasingly difficult, especially to meet the needs of higher education for their children, so that children who graduate from high school choose to work while studying. This causes campuses to seize this opportunity by providing employee classes or on weekends so that they can accommodate market needs, but still maintain quality standards, easy but not easy. About $45 \%$ of new students want night classes.
\end{abstract}

\section{Keywords: quality education, class employee}

\section{PENDAHULUAN}

Melihat kondisi ekonomi masyarakat yang semakin hari semakin sulit dalam memenuhi kebutuhan pokok karena harga barang-barang mengalami kenaikan. Hal ini tentunya memiliki dampak terhadap pemenuhan kebutuhan lainnya termasuk dalam memenuhi pendidikan anak mulai dari sekolah dasar hingga perguruan tinggi, hal ini juga berlaku bagi masyarakat yang ada di Kota Pekanbaru

Bagi mereka yang memiliki pendapatan upah minimum sesuai Keputusan Nomor : 880/XI/2017 Tentang UMK 2018 Tanggal 1 Januari 2018 sebesar Rp 2.557.486,73 yang memiliki 2 (dua) orang anak, merasakan betapa sulitnya memenuhi kebutuhan mereka hingga Sekolah Menengah Atas (SMA), apalagi untuk masuk perguruan tinggi sehingga ketika anak-anak mereka lulus SMA maka mereka dipersilahkan untuk bekerja diberbagai bidang.

Namun bagi mereka yang termasuk dalam keluarga yang cukup mapan maka masuk perguruan tinggi bukanlah permasalahan yang sulit bagi mereka, tinggal memilih universitas mana yang baik dari sisi kualitas dan mampu memberikan ilmu untuk anak mereka (Lai, 2014:605), namun bagi mereka yang berasal dari keluarga sederhana dan cenderung pas-pasan secara ekonomi maka faktor sosio-ekonomi juga menjadi pertimbangan untuk melanjutkan pendidikan tinggi atau cukup sampai SMA (HemsleyBrown, 2015:267). 
Sebagian dari mereka yang tidak mampu kuliah dari biaya orang tua, tentunya mereka memilih untuk bekerja terlebih dahulu sambil menabung untuk bisa kuliah. Ketika sudah memiliki tabungan, mereka tentu tidak bisa kuliah secara regular di pagi hari sebagaimana mahasiswa pada umumnya karena mereka bekerja dari hari senin hingga jumat dan bahkan ada yang bekerja hingga hari sabtu dari jam 8 pagi sampai jam 5 sore, mereka akan mencari alternatif kampus yang mengadakan perkuliahan dimalam hari atau di akhir pekan.

Adanya permintaan pasar untuk membuka kelas karyawan membuat beberapa perguruan tinggi di Kota Pekanbaru membuka kelas karyawan karena peminat kelas regular dengan kelas karyawan hampir sama besar antara $40 \%$ sampai $45 \%$ persen dari jumlah total mahasiwa setiap tahun ajaran baru.

Dibukanya kelas karyawan tidak semata hanya mencari income atau bisnis bagi perguruan tinggi atau institusi penyelenggaran pendidikan tinggi, tetapi juga wajib memperhatikan kualitas dari lulusan dan bagaimana proses belajar mengajar yang dilakukan.

Kita ketahui saat ini dunia pendidikan sudah menjadi lahan bisnis yang menggiurkan bagi para pemodal, tidak bisa dipungkiri dunia pendidikan bukanlah lembaga sosial yang mengratiskan biaya pendidikan, walaupun terdapat beberapa beasiswa yang ditawarkan. Namun dunia pendidikan sudah memasuki era industri pendidikan, walaupun demikian kualitas juga harus menjadi bahan pertimbangan dan harus diutamakan.

Terkadang tidak heran bahwa iklan yang ditawarkan untuk bisa kuliah dikelas karyawan pada sebuah perguruan tinggi sangat menarik, bahkan hanya dengan membayar Rp 500.000 sudah bisa kuliah, atau dengan slogan kampus nomor 1 (satu) disebuah kota, maka muncul pertanyaan "alat ukurnya apa sehingga meng-klaim sebagai kampus nomor 1", hal ini tentunya tidak menjadi masalah karena berbagai upaya dilakukan bagaimana bisa mendatangkan mahasiswa lebih banyak setiap tahunnya.
Untuk perguruan tinggi negeri (PTN) di kota Pekanbaru tidak memiliki kelas karyawan karena mereka sudah cukup penuh untuk menampung mahasiswa kelas non karyawan (Reguler), yang sering kekurangan mahasiswa adalah perguruan tinggi swasta (PTS), karena mereka juga membutuhkan biaya operasional.

Jika hanya mengandalkan kelas pagi, tentunya hal ini tidak mencukupi karena perbandingan non karyawan (Regular/non karyawan) dengan kelas malam (karyawan) hampir sama banyaknya, mau tidak mau mereka harus membuka kelas karyawan demi menjaga operasional agar tetap berjalan. Dengan uang kuliah yang ditawarkan berkisar mulai dari Rp 2.500.000 hingga Rp 3.500.000 tergantung kampus dan jurusan yang ingin diambil.

Tidak heran memang ketika dimalam hari beberapa kampus yang ada dikota pekanbaru terkadang lebih ramai jika dibandingkan dengan kelas dipagi hari, memang begitulah realita yang terjadi, permintaan untuk kelas karyawan begitu tinggi sehingga hal ini sangat antusias disambut oleh kampus-kampus seperti : Universitas Muhammadiyah Riau (UMRI), Universitas Lancang Kuning (Unilak), Universitas Abdurrab, Persada Bunda, Sekolah Tinggi Pelita Indonesia, STIE Riau Akbar dan beberapa sekolah tinggi lainnya yang menangkap peluang ini. Secara garis besar orientasi calon mahasiswa yang berprofesi sebagai karyawan dalam menentukan pilihan perguruan tinggi yang akan dipilih untuk melanjutkan studi Strata Satu (S1), menjadi bahan acuan oleh perguruan tinggi dalam membuka kelas karyawan.

Tingginya permintaan kelas karyawan juga harus diimbangi dengan kualitas lulusan nantinya, kampus jangan hanya menjadi tempat produksi uang tetapi juga mengedepankan aspek keilmuan.

\section{PEMBAHASAN}


Sejak tahun ajaran 2016-2017 diberlakukan larangan untuk membuka kelas pada hari minggu dan juga kelas jarak jauh, ini berlaku untuk semua perguruan tinggi di Indonesia. Di Hongkong juga dilakukan pengaturan untuk kelas-kelas khusus seperti kelas jauh (Chiu, 1999:26-33). Hal ini disatu sisi bertujuan untuk menjaga agar tidak ada eksploitasi dunia pendidikan terlalu berlebihan dimana jam kerja perguruan tinggi yang begitu padat dari hari senin hingga minggu, padahal lazimnya untuk perusahaanperusahaan swasta adalah senin hingga jumat dari jam $08.00-17.00$ WIB. Sehingga kampus mencari alternatif memindahkan jadwal kuliah hari minggu menjadi hari jumat. Tentunya aturan yang dibuat pemerintah sudah melalui tahapan evaluasi dan diskusi karena memperhatikan pertimbangan berbabai pihak (Pfeffermann, 2016:866)

Disisi lain memang untuk mahasiswa yang berprofesi sebagai karyawan tentunya ini menjadi dilema, karena waktu mereka yang bisa dipergunakan untuk kuliah adalah Sabtu dan Minggu, sedangkan hari Jumat mereka masih bekerja terkadang hingga malam hari. Pada akhirnya jurus terakhir yang dipakai adalah pandai-pandai mengatur waktu kerja dan kuliah asalkan tidak terlalu berlebihan.

Segmentasi calon mahasiswa yang akan memilih perguruan tinggi dapat dibedakan menjadi dua yaitu mahasiswa reguler dan mahasiswa karyawan. Dengan pertimbangan yang berbeda sesuai dengan latar belakang calon mahasiswa tersebut.

\subsection{Mahasiswa Reguler}

Bagi mereka yang bukan berprofesi sebagai karyawan tentunya dalam menentukan pilihan universitas lebih cenderung kepada kualitas dari perguruan tinggi yang akan dituju. Survey yang dilakukan terhadap mahasiswa semester 2 yang sudah menempuh perkuliahan. Dapat dilihat pada tabel 1 dibawah ini

Tabel 1. Orientasi kelas reguler Memilih PTS

\begin{tabular}{|c|l|c|c|}
\hline No & \multicolumn{1}{|c|}{ Alasan } & Jumlah & Persentase \\
\hline 1 & Dekat rumah & 22 & $13,33 \%$ \\
\hline 2 & Biaya terjangkau & 34 & $20,61 \%$ \\
\hline 3 & Iklan Koran & & \\
\hline 4 & Baliho Jalan Raya & 4 & $2,42 \%$ \\
\hline 5 & Akreditasi & 60 & $36,36 \%$ \\
\hline 6 & Fasilitas Kampus & 3 & $1,82 \%$ \\
\hline 7 & Pilihan Orang tua & 18 & $10,91 \%$ \\
\hline 8 & Ikut Teman Kampung & & \\
\hline 9 & Peran Alumni & 9 & $5,45 \%$ \\
\hline 10 & Adanya kelas malam & 15 & $9,09 \%$ \\
\hline \multicolumn{2}{|c|}{ Total } & 165 & $100 \%$ \\
\hline \multicolumn{2}{|c|}{} \\
\end{tabular}

Faktor jarak antara rumah dengan kampus menjadi pilihan mahasiswa yang tidak ingin pergi kuliah terlalu jauh, rata-rata jarak rumah mahasiswa dengan kampus berkisar antara $7-8 \mathrm{KM}$

Biaya yang terjangkau juga menjadi pilihan calon mahasiswa karena rata-rata uang kuliah Rp 2.500.000 s/d Rp 3.500.000 yang berlaku untuk Universitas Lancang Kuning (Unilak), Universitas Muhammadiyah Riau (UMRI), Universitas Abdurrab, Sekolah Tinggi Pelita Indonesia, STIE Riau Akbar dan beberapa kampus lainnya. Faktor biaya tidak bisa terlepas dari salah satu yang menentukan seseorang memilih tempat pendidikan (Chulkov, 2014:184-185) karena selain biaya tetap, nanti akan ada biaya tambahannya seperti buku dan penunjang lainnya. Tentunya ini juga menjadi pertimbangan, ketika biaya kuliah terlalu tinggi maka akan berdampak pada kemampuan ekonomi orang tua dari mahasiswa tersebut.

Baliho yang dipasang dipinggir jalan ternyata kurang efektif dalam memikat mahasiswa dan ini terlihat dari jawaban mahasiswa bahwa mereka kurang memperhatikan iklan-iklan dijalan raya, karena fokus dijalan raya rata-rata untuk berkendaraan. Untuk negara asean lainnya seperti Vietnam dimana iklan masih menjadi pertimbangan mahasiswa dalam menentukan pilihan universitas (Dao, 2015:676).

Point akreditasi menjadi perhatian mahasiswa dalam memilih kampus, dengan pertimbangan bahwa ketika lulus mereka bisa ikut CPNS dan perusahaan-perusahaan yang berkualitas. Sebagaimana yang dinyatakan oleh Lock (1999:75) bahwa akreditas menjadi bagian yang tidak terpisahkan dari badan akreditasi, sebagai pertimbangan layak atau 
tidak sebuah institusi menyelenggarakan program pendidikan. Hal ini untuk memastikan apakah kampus tersebut bisa bertahan lama dimasa depan (Anninos, 2012:61-75)

Fasilitas kampus menjadi pilihan kesekian bagi mahasiswa dalam memilih kampus, karena mereka berpendapat bahwa jika akreditasi kampus minimal B maka fasilitas yang ada tidak akan terlalu jelek. Pandangan mereka bahwa akreditasi yang baik tentunya ditunjang dengan fasilitas yang baik, karena itulah mereka tidak terlalu memperhatikan aspek fasilitas. Seperti hal nya negara di Asia Pacifik bahwa para mahasiswa memilih kampus yang terbaik untuk menentukan dimasa depan dimana mereka bekerja (Gniewosz, 1998:143-162). Namun ada yang menarik bahwa kualitas dalam sudut pandang para mahasiswa adalah bagaimana cara pelayanan yang mereka dapatkan dari pihak kampus (Matzdorf, 2003:219-220).

Bagi mahasiswa yang mengikuti keinginan orang tua dalam memilih perguruan tinggi dipengaruhi oleh beberapa faktor seperti anak perempuan, orang tua punya kedekatan emosional dengan orang-orang yang bekerja dikampus tersebut. Dalci (2018:191-192) dalam penelitiannya menemukan bahwa peran orang tua dalam membimbing anaknya memilih universitas juga terkait karir anak dimasa depan.

Peran alumni hanya $5,45 \%$ dalam mempengaruhi mahasiswa dalam memilih perguruan tinggi, sebenarnya disini bisa ditingkatkan menjadi 20\% hingga 30\% karena dengan peran alumni yang sudah bekerja diberbagai bidang, bisa menjadi alat ukur kesuksesan alumni sebuah perguruan tinggi. Promosi memalui alumni seharusnya bisa menjadi daya tarik karena mereka adalah bukti nyata hasil pendidikan sebuah perguruan tinggi, memang tidak semua mereka mampu mencapai puncak karir namun bisa menjadi representasi dari kualitas sebuah universitas.

Mahasiswa yang memilih untuk adanya kelas malam sebesar 9,09\% karena mereka berkeinginan pindah kelas jika mendapatkan pekerjaan, karena memang ketika para mahasiswa sudah masuk semester 3 atau 4 mereka mencoba mencari pekerjaan, sehingga ketika mereka mendapatkan pekerjaan, mereka akan pindah jadwal dikelas malam. Terkadang mahasiswa tidak selamanya ingin menggantungkan hidup dengan biaya orang tua, atau kondisi keuangan orang tua dikampung mulai tidak baik karena beban hidup keluarga yang makin besar, hal inilah yang mendorong mereka yang tadinya mengambil kuliah saja, mulai berpikir mencari pekerjaan untuk mendapatkan penghasilan, ketika sudah mendapatkan pekerjaan maka mereka akan pindah jadwal kelas malam.

\subsection{Mahasiswa Karyawan}

Untuk melihat pilihan mahasiswa kelas karyawan dalam memilih perguruan tinggi maka dilakukan survey secara acak terhadap 150 mahasiswa semester 2 (dua), dapat dilihat pada tabel 2 berikut :

Tabel 2. Orientasi Karyawan Memilih PTS

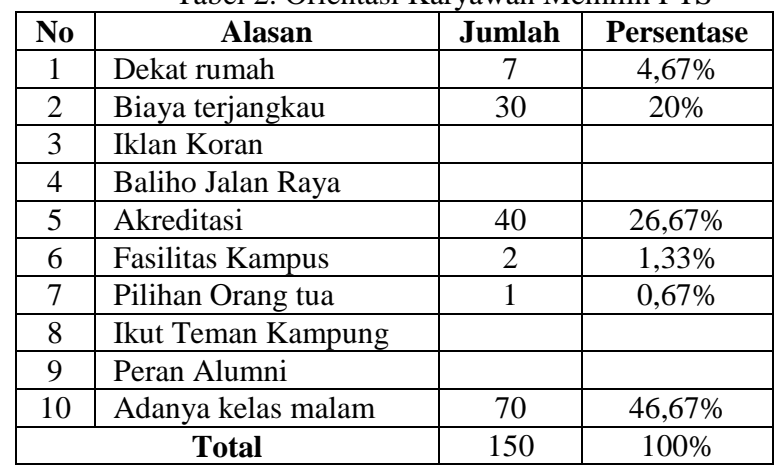

Mahasiswa yang berprofesi sebagai karyawan terlihat berbeda dalam menentukan pilihan kampus, mereka cenderung untuk memilih kampus yang membuka kelas malam yaitu sebesar $46,67 \%$ sedangkan sebesar $26,67 \%$ memilih berdasarkan akreditasi kampus tersebut.

Mereka yang memilih karena melihat akreditasi kampus, rata-rata ingin menekuni bidang tertentu seperti akuntansi (Tang, 2016:244-245) dan tentunya mereka ingin hasil yang terbaik, apalagi lulusan-lulusan muda menjadi prioritas dunia kerja (Tansel, 2003:52-69). 
Artinya bahwa kebutuhan kelas karyawan dan akreditasi tetap menjadi prioritas, baik antara mahasiswa kelas regular maupun kelas karyawan, mereka yang bekerja sambil kuliah memiliki keinginan untuk merubah nasib dan jenjang karir dimasa depan, maka dari itu mereka juga perlu mendapatkan ilmu dari kampus yang memiliki reputasi yang bagus.

Alfattal (2017:940) menyatakan pemasaran program menjadi daya tarik kepada calon mahasiswa, seperti halnya tawaran kelas khusus karyawan. Kekuatan pasar ini merupakan kebutuhan yang tidak bisa dihindari dan memiliki nilai jual (Haw, 2016: 443-475; Veloutsou, 2005:289). Potensi mahasiswa kelas karyawan ini harus ditangkap karena ini pasar yang sangat potensial, dimana tingginya permintaan dan diimbangi dengan penawaran dari pihak kampus (Brown, 2009:321-322) serta bersaing secara sehat agar menciptakan competitive market (Maringe, 2006:466).

Walapun masih ada yang berpendapat bahwa yang penting bisa dapat $\mathrm{S} 1$ dan kuliahnya tidak susah, hal ini masih juga beredar dikalangan mahasiswa kelas karyawan, disinilah diperlukan konsistensi perguruan tinggi untuk menjaga reputasi, jangan sampai dikatakan kampus gampangan dan murahan.

\subsection{Bisnis Pendidikan}

Bajada (2016:462) menyatakan bahwa perlu dilakukan pendekatan kurikulum, hal ini sebagai antisipasi perkembangan pasar dunia pendidikan. Menggabungkan Paradigma tradisional dan modern memiliki tantangan tersendiri (Laughton, 2000:378). Hal ini yang dialami pendidikan bisnis di Jepang dimana karyawan lebih memiliki inisiatif untuk menempuh pendidikan professional, kesadaran kaum muda merupakan tuntutan zaman digital (Kobayasi, 1996:30-37). Untuk menyusun kurikulum tersebut dibutuhkan tim dan kepemimpinan yang professional (Witte, 2014: 357-373) sehingga mampu menghasilkan nilai positif.

Philips (2000:150) juga menyebutkan bahwa marketing education berperan dalam menggaet mahasiswa, marketing yang selama ini hanya lazim dalam dunia usaha, namun dalam bisnis pendidikan mutlak diperlukan marketing dalam promosi, namun marketing disini bukan semata berbicara iklan, tetapi mendekatkan institusi pendidikan kepada masyarakat melalui program-program edukatif dan menjalankan misi sosial (Jurse, 2011:1452).

Naeem (2012:68) juga menyatakan pentinganya unsur keberlangsungan daripada hanya sekedar aspek bisnis. Jika kampus tersebut hanya bertahan beberapa tahun maka yang akan merasakan dampaknya adalah para alumni, untuk itu perlu menjaga kualitas organisasi dan tertib secara administrasi (Joseph, 2000:42-43).

Terkadang bisnis juga harus diseleraskan dengan budaya masyarakat tersebut (James-MacEachern, 2017:357), beberapa lembaga pendidikan juga masih didominasi oleh etnis tertentu, sehingga bagi mereka yang berasal dari etnis akan merasa kurang nyaman. Maka dari itu bermunculan sekolah dengan latar belakang etnis dan ini tidak bisa kita pungkiri. Ini terbentuk melalui persepsi dimasyarakat (Seeley, 2018:329) dan ini dimanfaatkan oleh kampus tersebut untuk menggaet pasar dengan segment etnis.

Siapa yang tidak mampu bersaing maka akan tertinggal (Joseph, 1998:90-94), begitulah prinsip dalam bisnis pendidikan zaman know.

\subsection{Kualitas Lulusan}

Pentingnya menjaga kualitas para lulusan yang berkemampuan internasional (Silvanto, 2017:45) karena kompetisi lulusan bukan hanya berbicara area lokal tetapi sudah masuk dunia internasional ( Lorange, 2003:132), persaingan karir dimasa depan akan semakin komplek maka dari itu para mahasiswa juga memikirkan karir mereka nanti ditempat bekerja (Taryid, 2017:10351036; Dalc1, 2013:160). Lulusan yang dibekali kemampuan Bahasa inggris akan memberikan nilai lebih bagi penerima kerja nantinya, tidak susah dalam mempelajarinya karena yang menjadi hambatan adalah dari mahasiswanya sendiri (Lee, 2016:165). 
Graham (1991:27-38) dan Vaarmets (2018:380-393) menyatakan bahwa lulusan yang sudah dewasa tentunya akan berpikir tentang karir yang akan ditekuni pasca lulus, maka dari itu proses yang dilalui ketika perkuliahan sangat menentukan. Jika proses yang dilalui dilakukan dengan mendidik mahasiswa untuk mandiri, bertanggung jawab, berintegritas dan memiliki nilai jual maka para lulusan tidak akan sulit mencari pekerjaan pasca lulus.

Proses yang baik tentu dimulai dengan kualitas dosen yang baik (Soutar, 2002:44-45) karena ilmu itu diturunkan dari mereka kepada mahasiswa. Terkadang sebagian dosen malas untuk memperbaharui keilmuan yang dimiliki, merasa cukup dengan bahan perkuliahaan yang ada, padahal sejatinya ilmu itu terus berkembang dan minimal 3 tahun perlu dilakukan revisi materi kuliah yang akan disampaikan. Bagaimana mungkin dosen bisa memberikan ilmu yang update sementara bahan ajar yang dimiliki sama dengan 5 (lima) tahun yang lalu dan tidak diperbaharui sedikitpun. Tidak sedikit dosen masih menitik beratkan porsi penilaian pada ujian tertulis Ujian Tengah Semester (UTS) dan Ujian Akhir Semester (UAS) dengan persentase mencapai 50\% (lima puluh persen) dari total penilaian.

Kita bisa lihat banyaknya pengangguran disekitar bahkan mereka yang bertitel sarjanapun ikut menganggur, padahal mereka dibekali ilmu bahkan digadanggadang bisa membuka lapangan pekerjaan dengan bekal yang dimiliki. Belum banyak perguruan tinggi mencetak mahasiswa yang berkarakter pengusaha tetapi lebih pada pekerja kantoran. Hal ini tidak lepas dari budaya (Yao, 2016:60) dalam masyarakat yang memandang kesuksesan itu jika bekerja dengan seragam, rapi dan bekerja dikantoran.

Tetapi sebaliknya jika ada sarjana yang mengabdi di desa menjadi peternak maka ini menjadi cibiran dimasyarakat "masa sarjana jadi peternak". Padahal tidak semua sarjana itu harus bekerja dikantoran, mereka juga harus diterjunkan didalam masyarakat untuk menjadi pendamping dengan keilmuan yang mereka miliki agar mampu mengangkat taraf hidup masyarakat tersebut.

\subsection{Harga dan Kualitas}

Sebuah slogan "ada harga ada rupa", tentunya kita sepakat dengan slogan ini, sesuatu yang berkualitas tidak mungkin diobral sebegitu murah. begitu juga dengan dunia pendidikan, dimana penunjang dalam perkuliahan dibidang eksakta membutuhkan alat-alat praktikum, uji laboratorium dan lainnya, dibutuhkan biaya yang cukup tinggi untuk peralatan yang berkualitas. Untuk saat ini fakultas favorit pilihan mahasiswa adalah Ekonomi, Hukum dan Ilmu Komputer (Suci, 2018:162), tentunya ketiga fakultas ini juga membutuhkan pengembangan fasilitas belajar mengajar yang lebih modern dan kompetitif.

Ini kembali lagi kepada motif dan kesempatan yang ada dimasyarakat (Hall, 1997:83-92), karena pola pikir masyarakat tidak bisa kita kendalikan, disisi lain sudah ada yang sadar akan korelasi harga dan kualitas sedangkan pada sisi lain masih memandang harga dan bukan kualitas. Ini hak preogratif masyarakat dan tidak bisa kita hakimi benar atau salah karena disesuaikan dengan kemampuan ekonomi masing-masing.

Widayat (2018:71-72) menyatakan bahwa biaya dan kualitas tidak bisa dipisahkan. Setiap perguruan tinggi punya formula masing-masing dalam menentukan biaya pendidikan (Amir, 2016:929-937), dengan mempertimbangkan tingkat inflasi, kondisi ekonomi penduduk lokal dan juga kualitas akreditasi program studi di perguruan tinggi tersebut. Program studi dengan akreditasi A tentunya memiliki biaya kuliah yang lebih tinggi jika dibandingkan dengan program studi dengan akreditasi $\mathrm{B}$.

Tak heran terkadang perguruan tinggi terjebak dalam politik organisasi kampus, dimana menempatkan orang-orang berdasarkan kedekatan emosional (Suci, 2018:6-8), bagaimana kita akan berbicara peningkatan kualitas internal sedangkan cara menempatkan seseorang bukan berdasarkan kompetensi tetapi kedekatan diri.

Pada akhirnya salah menerapkan strategi pemasaran, terkadang kita terjebak 
dalam permainan harga, dengan menggadaikan nilai sebuah institusi pendidikan, sah-sah saja perang harga agar calon mahasiswa tertarik namun seharusnya bukan itu yang harus dilakukan perguruan tinggi. Seharusnya perguruan tinggi lebih menonjolkan sisi akademis dan kualitas yang dimiliki sesuai dengan kapasitas, jangan menjual "angin syurga" yang hanya numpang lewat.

\section{SIMPULAN}

Orientasi dalam memilih perguruan tinggi antara mahasiswa kelas regular dengan kelas karyawan hampir sama tetapi terdapat beberapa faktor yang lebih utama. Untuk mahasiswa kelas regular yang menjadi orientasi utamanya adalah bagaimanan akreditasi perguruan tinggi, setelah itu baru pertimbangan biaya menjadi alasan dalam memilih perguruan tinggi swasta.

Untuk mahasiswa kelas karyawan yang menjadi pertimbangan dalam memilih perguruan tinggi adalah adanya kelas karyawan dan kemudian akreditasi yang lebih baik (minimal B). Bagaimanapun bagusnya akreditasi kampus tersebut tetapi jika tidak membuka kelas karyawan, otomatis tidak akan bisa menampung mahasiswa kelas karyawan.

Secara keseluruhan pertimbangan memilih perguruan tinggi swasta, antara mahasiswa kelas regular dan kelas karyawan adalah berdasarkan akreditasi, adanya kelas karyawan, uang kuliah yang terjangkau dan lokasi yang dekat dengan rumah.

\section{DAFTAR PUSTAKA}

Alfattal, Eyad. 2017. International students' college choice is different. International Journal of Educational Management, Volume: 31 Issue: 7.

Amir, Amizawati Mohd., Sofiah Md Auzair., Ruhanita Maelah., Azlina Ahmad. 2016. Pricing for higher education institutions: a value-based approach. International Journal of Educational Management, Volume: 30 Issue: 6.
Anninos, Loukas N., Leonidas S., Chytiris. 2012. The sustainable management vision for excellence: implications for business education. International Journal of Quality and Service Sciences, Vol. 4 Issue: 1, pp.61-75.

Bajada, Christopher., Rowan Trayler. 2016 Introduction to threshold concepts in business education. Education Training, Volume: 58 Issue: 5.

Brown, Claire., Peter Varley, John Pal. 2009. University course selection and services marketing. Marketing Intelligence \& Planning, Volume: 27 Issue: 3.

Chiu, Randy. 1999. Relationships between motivators and criteria in the selection of a distance learning MBA programme in Hong Kong. Career Development International, Vol. 4 Issue: 1, pp.26-33.

Chulkov, Dmitriy., Jason VanAlstine. 2014. The impact of multiple textbook format availability in business education. Journal of Applied Research in Higher Education, Volume: 6 Issue: 1.

Dalci, İlhan., Hasan Özyapici. 2018. Cultural values and students' intentions of choosing accounting career. Journal of Financial Reporting and Accounting, Volume: 16 Issue: 1.

Dao, Mai Thi Ngo., Anthony Thorpe. 2015. What factors influence Vietnamese students' choice ofuniversity. International Journal of Educational Management, Volume: 29 Issue: 5.

Dalci., İlhan., Huseyin Araslı., Mustafa Tümer., Sarvnaz Baradarani. 2013. Factors that influence Iranian students' decision to chooseaccounting major. Journal of Accounting in Emerging Economies, Volume: 3 Issue: 2.

Gniewosz, Gerhard. 1998. Professional Aspriations and Preferences of South Pacific Accounting Students: A Comparative Analysis. Asian Review of Accounting, Vol. 6 Issue: 2, pp.143-162.

Graham, Barbara. 1991. Career Choices of Older Graduates. International Journal of Manpower, Vol. 12 Issue: 5, pp.27-38. Hall, Jhon., Michael Shaw., Isobel Doole. 1997. Cross-cultural Analysis of Wine 
Consumption Motivations. International Journal of Wine Marketing, Vol. 9 Issue: 2, pp.83-92.

Haw, In-Mu., Bingbing Hu., Jay Junghun Lee., Woody Wu. 2016. The impact of industry concentration on the market's ability to anticipate future earnings: International evidence. International Journal of Accounting \& Information Management, Vol. 24 Issue: 4, pp.443475.

Hemsley-Brown, Jane.,Izhar Oplatka. 2015. University choice: what do we know, what don't we know and what do we still need to find out. International Journal of Educational Management, Volume: 29 Issue: 3.

James-MacEachern, Melissa., Dongkoo Yun. 2017. Exploring factors influencing international students' decision tochoose a higher education institution: A comparison between Chinese and other students. International Journal of Educational Management, Volume: 31 Issue: 3.

Joseph, Mathew., Beatriz Joseph. 1998. Identifying needs of potential students in tertiary education for strategy development. Quality Assurance in Education, Volume: 6 Issue: 2.

Joseph, Mathew., Beatriz Joseph. 2000. Indonesian students' perceptions of choice criteria in the selection of a tertiary institution: strategic implications. International Journal of Educational Management, Volume: 14 Issue: 1.

Jurše, Milan., Matjaž Mulej. 2011. The complexities of business school alignment with the emerging globalisation of business education. Kybernetes, Volume: 40 Issue: 9/10.

Kobayashi, Kaoru. 1996. Adult business education programmes in private educational institutions in Japan. Journal of Management Development, Vol. 15 Issue: 8, pp.30-37.

Lai, Angel Po Cheung Lai., Paul Gibson., Siva Muthaly. 2014. Becoming an education provider of choice in Hong
Kong: an inquiry into student decision making. International Journal of Educational Management, Volume: 28 Issue: 5.

Laugthon, David., Roger Ottewill. 2000. Developing cross - cultural capability in undergraduate businesseducation: implications for the student experience. Education Training, Volume: 42 Issue: 6.

Lee, Kang-Young., Randy Warren Green. 2016. The World Englishes paradigm: A study of Korean universitystudents' perceptions and attitudes. English Teaching: Practice \& Critique, Volume: 15 Issue: 1.

Lock, Andrew. 1999. Accreditation in business education. Quality Assurance in Education, Volume: 7 Issue: 2.

Lorange, Peter. 2003. Case study: Global responsibility

- business education andbusiness school $s$ - roles in promoting a global perspective. The international journal of business in society, Volume: 3 Issue: 3.

Maringe, Felix. 2006. University and course choice: Implications for positioning, recruitment and marketing. International Journal of Educational Management, Volume: 20 Issue: 6.

Matzdorf, Fides., Louise Smith., Helen Agahi. 2003. The impact of facilities on student choice of university. Facilities, Volume: 21 Issue: 10.

Naeem, Malik., Mark Neal. 2012. Sustainability in business education in the Asia Pacific region: a snapshot of the situation. International Journal of Sustainability in Higher Education, Volume: 13 Issue: 1.

Pfeffermann, Guy. 2016. GBSN's perspective on business education and globalization, Journal of Management Development, Vol. 35 Issue: 7, pp.866877.

Phillips, Melodie R., Veronica Horton. Cybercheating: has morality evaporated in business education. 2000. International Journal of Educational Management, Volume: 14 Issue: 4. 
Seeley,

Eugene

Lyle., Todd

Goddard., Ronald Mellado Miller. 2018.

Ge-whiz! How students choose their general education classes. Journal of Applied Research in Higher Education, Volume: 10 Issue: 3.

Silvanto, Sari., Jason Ryan., Vipin Gupta. 2017. A study of the impact of business education on global career mobility: An analysis of location and international orientation. Journal of International Education in Business, Volume: 10 Issue: 1.

Soutar, Geoffrey N., Julia P. Turner. 2002. Students' preferences for university: a conjoint analysis. International Journal of Educational Management, Volume: 16 Issue: 1.

Suci, Afred. Penjaminan mutu perguruan tinggi : Dilema politik organisasi dan urgensi penggunaan profesional eksternal. Jurnal Penjaminan Mutu IHDN Vol 3 No 2 Agustus 2017.

Suci, Afred., Junaidi. 2018. Pemetaan Daya Saing Internal Universitas Lancang Kuning. Jurnal Daya Saing. Volume 4 Nomor 2 Juni pp. 153-164.

Tansel, Aysit., Nil Demet Güngör. 2003. Brain drain" from Turkey: survey evidence of student non- return. Career Development International, Vol. 8 Issue: 2, pp.52-69.

Tang, Lim Chhoung., Cheaseth Seng. 2016. Factors influence students' choice of accounting major in Cambodian universities. Asian Review of Accounting, Volume: 24 Issue: 2.

Tarvid, Alexander. 2017. Attracting doctoral students: case of Baltic universities. International Journal of Educational Management, Volume: 31 Issue: 7.

Vaarmets, Tarvo. 2018. Gender, academic abilities and postsecondary educational choices. Journal of Applied Research in Higher Education, Volume: 10 Issue: 3.

Veloutsou, Cleopatra., Robert A. Paton., John Lewis. 2005. Consultation and reliability of information sources pertaining touniversity selection: Some questions answered. International Journal of
Educational Management, Volume: 19 Issue: 4.

Widayat, Prama. 2018. Manajemen Risiko dan Asuransi dalam Praktek edisi revisi. Hanum Publisher. Jawa Tengah.

Widayat, Prama. 2018. Between cost chep prices and increasing high quality educational university in pekanbaru city. Jurnal Penjaminan Mutu. Volume 4 Nomor 1 Februari pp. 67-75. 